\title{
DINAMIKA KEAGAMAAN MASYARAKAT PERBATASAN PALOH KABUPATEN SAMBAS, KALIMANTAN BARAT
}

\author{
Aslan $\left(\mathbf{( ~}^{*}\right)$,Suhari $\left({ }^{2}\right)$, Antoni $\left({ }^{3}\right)$, M. Ali Mauludin $\left({ }^{4}\right)$ ' Galuh Nashrulloh Kartika MR $\left(^{5}\right)$ \\ 12 Institut Agama Islam Sultan Muhammad Syafiuddin Sambas, Kalimantan Barat, Indonesia. \\ 3 Universitas Wijaya Putra, Surabaya, Jawa Timur, Indonesia. \\ 4 Laboratorium Sosiologi dan Penyuluhan Universitas Padjadjaran Bandung, Jawa Barat, Indonesia. \\ 5 UNISKA Muhammad Arsyad Al-Banjari Banjarmasin, Kalimantan Selatan, Indonesia.
}

\begin{tabular}{|c|c|}
\hline \multicolumn{2}{|c|}{ ARTICLE INFORMATION } \\
\hline $\begin{array}{l}\text { Submitted } \\
\text { Review I } \\
\text { Accepted } \\
\text { Published } \\
\text { Available Online }\end{array}$ & $\begin{array}{l}: 20^{\text {th }} \text { December, } 2019 \\
: 05^{\text {th }} \text { February, } 2020 \\
: 04^{\text {th }} \text { May, } 2020 \\
: 1^{\text {st }} \text { June, } 2020 \\
: \text { June, } 2020\end{array}$ \\
\hline KEYWORDS & \\
\hline
\end{tabular}

Religious Dynamics; Paloh Border Community; Sambas Regency

\section{CORRESPONDENCE}

*E-mail: aslanmarani88@yahoo.com

\begin{abstract}
A B S T R A C T
Paloh is an unseen tribe in the City of Truth or a place where Bunians are believed to have supernatural powers up to now from Kalimantan and its surroundings. The purpose of this study is to describe the Paloh community's belief in the existence of the City of Truth inhabited by subtle people, which isinvisible to the presence of the City of Truth. However, in the eyes of the mind, Paloh is a city for magical creatures that are more beautiful, majestic, luxurious, complete facilities and infrastructure compared to West Kalimantan. To obtain the required data, a series of Paloh community interviews, field observations and documentation have been successfully carried out. The results of this study include that the Paloh people who are still thick with sacred values believe that the Paloh area is the City of Truth. So that the Paloh community still applies restrictions and prohibitions that cannot be violated by anyone who comes to the Paloh forest. If there are people who violate restrictions and prohibitions, then they will receive the consequences in the form of illness, mental disorders such as crazy, stress and even to death. Therefore, Paloh is called the Truth Person, because if they come there with no good intentions, they will be warned by the Bunian people. On this basis, so that now Paloh is still known as the City of Prohibition for those who are intended to do wrong and evil.
\end{abstract}

\section{A. PENDAHULUAN}

erubahan adalah niscaya yang terjadi dalam kehidupan masyarakat. Perubahan tidak terlepas dari perjalanan sejarah manusia dengan mengalami beberapa rentetan, sehingga setiap rentetan akan mengalami perbedaan dari rentetan sebelumnya. Oleh karena itu, banyak para pemikir-pemikir sosial memaknai perubahan dengan berbagai macam perbedaan, tetapi disatu sisi tidak terlepas dari persamaan, yang mana perubahan yang dialami masyarakat nantinya akan segala-galanya berubah.

Sztompka (1993), Aslan \& Hifza (2020), dalam memaknai perubahan tidak terlepas dari sejarah yang telah dialami manusia. Sementara, Toffler (1970) (1980), membagi perubahan dengan mengalami tiga masa, yang dimulai masa pertanian, industri dan masa sekarang.
Dari ketiga masa perubahan tersebut masingmasing mengalami perbedaan dan dampak dari perubahan yang dialami oleh masyarakat, misalnya pada era pertanian, teknologi masih sederhana, era industri teknologi sudah mulai canggih, tetapi mengalami keterbatasan bagi masyarakat untuk menikmatinya. Pada saat manusia hidup di era sekarang, maka teknologi suda berlimpah ruah, sehingga dalam buku selanjutnya, Toffler mengatakan bahwa perubahan di era sekarang telah mengejutkan manusia dari segala-galanya.

Teknologi mutakhir dalam kehidupan manusia saat ini adalah internet. (Mujiburrahman, 2017); (Mujiburrahman, 2017); (Aslan, 2019). Perkembangan teknologi yang dianggap mutakhir telah membawa manusia hidup di alam dua dunia, yakni maya dan nyata sekaligus dunia maya telah banyak menaburkan pesona kepada 
manusia, sehingga dari pesona tersebut manusia lebih lebih banyak hidup di dunia maya dibandingkan dengan dunia nyata. (Mujiburrahman, 2018). Salah satunya fitur yang dihasilkan oleh smartphone saat ini adalah instagram. Instagram disatu sisi mampu membuat manusia semakin percaya diri, tetapi disisi lain mempunyai dampak negatif. (Roem \& Sarmiati, 2019). Perbedaan perubahan yang dialami masyarakat, sehingga pandangan dalam agamapun ikut juga mengalami perubahan, yang mana setiap teknologi dari media siaran televisi yang hadir dalam kehidupan masyarakat dengan mengundang ustadz dan ustadzah dengan pemahaman agama yang berbeda-beda. (Mujiburrahman, 2015). Pada era tahun 80-an, media televisi sangat jarang sekali dimiliki oleh masyarakat. Televisi hanya dimiliki oleh masyarakat dari kalangan tertentu. Akan tetapi, saat ini tidak dapat lagi dipungkiri, televisi sudah membanjiri rumah masyarakat yang tidak lagi mengenal tempat tinggal masyarakat dan kalangan strata masyarakat yang bersangkutan. Namun, dampak dari perubahan era informasi saat ini, hubungan agama dengan masyarakat tidak terlepas dari tiga pandangan.

Menurut Thomas F. O'Dea (1996), Nottingham (1996), hubungan manusia terhadap agama terdiri dari tiga aspek; Pertama, agama merupakan kesadaran yang tertinggi yang dimiliki oleh manusia. Kedua, agama menyangkut pandangan yang suci bagi masyarakat. Ketiga, masyarakat dalam beragama tidak terlepas dari keyakinan yang dianggap supranatural yang tidak bisa dibuktikan secara empiris. Ketiga aspek tersebut, hubungan agama dengan masyarakat terdapat perbedaan yang dimiliki oleh masyarakat yang bersangkutan. Apalagi, masyarakat yang tinggal di desa, masih dianggap sebagai masyarakat yang masih kental terhadap kepercayaan nenek moyang atau agama animisme dan dinamisme.

Dinamika keagamaan masyarkat dari hubungan agama dan masyarakat, pada awalnya sebelum berkembangnya teknologi, masyarakat sudah mempunyai pola pemikiran yang terikat dalam hubungannya sesama masyarakat yang diciptakan oleh masyarakat untuk membuat aturan dalam kehidupan suatu masyarakat yang terikat oleh nilai. (Agus Salim, 2014). Nilai yang diciptakan oleh masyarakat yang bersangkutan, sehingga membedakan juga terhadap nilai agama yang dimiliki oleh masyarakat antara daerah yang satu dengan yang lainnya.

Perbedaan ini, dianggap oleh Alfani Daud (1997), sebagai "religi komunitas" yang memberikan identitas pada masyarakat lain, diantaranya; Pertama, percaya dari sumber ajaran Islam. Kedua, percaya kepada yang gaib. Ketiga, kepercayaan terhadap lingkungan. Oleh karena itu, masyarakat dalam beragama tidak terlepas kepada sesuatu yang sakral dan profan.
Menurut Durkheim, agama yang sakral adalah sesuatu tanpa adanya perubahan, suci, tidak boleh dilanggar dan apabila dilakukan maka akan mendapatkan mara bahaya, yang bisa juga berbentuk tempat, binatang, tumbuhan, maupun lainnya. Sementara, yang profan adalah sesuatu yang telah mengalami perubahan dan sudah boleh dilangar atau sudah tidak lagi dianggap tabu. (Pals, 2012). Agama yang masih sakral, banyak ditemukan pada masayarakat primitif pada zaman dahulu, dibandingkan pada zaman informasi saat ini. (Rakhmat, 2013). Masyarakat yang dianggap primitif adalah masyarakat yang hidup paling sederhana yang cenderung tinggal di daerah pedesaan, dibandingkan dengan masyarakat yang tinggal di perkotaan. (Sanaky, 2005). Akan tetapi, tidak semuanya masyarakat dengan berbagai etnik yang ada di Indonesia, khususnya masyarakat Sambas di Paloh mengalami perubahan dari sistem kepercayaan yang dianutnya, seperti halnya yang dilakukan penelitian oleh Langaji, (2016) tentang dinamika keagamaan dengan adanya perbedaan aliran dalam memahami agama.

Dinamika keagamaan adalah sebuah gambaran tentang kehidupan masyarakat tentang keyakinan dan interaksi sosial dari keyakinan tersebut. (Ridwan, 2016). Setiap keyakinan yang dimiliki mengalami perubahan sesuai dengan perkembangan politik di masyarakat. (Agustono, 2016). Perubahan dalam beragama tersebut dikenal sebagai otoritas agama. Disatu sisi agama adalah kepercayaan terhadap Tuhan, tetapi disisi lain agama adalah milik individu yang selalu mengalami perubahan. (Rumadi, 2012). Secara umum, kepercayaan agama secara individu dimiliki oleh setiap masyarakat yang ada di dunia, tetapi berbeda halnya dengan masyarakat yang ada di Paloh, yang mana hampir secara keseluruhan masyarakat Paloh masih mempercayai agama nenek moyang.

Paloh merupakan wilayah Kecamatan Sambas, Provinsi Kalimantan Barat. Kabupaten Sambas merupakan salah satu daerah Tingkat II Provinsi Kalimantan Barat, dengan luas wilayah $6.395,70 \mathrm{~km}^{2}$ atau 639.570 ha (4,36 dari luar wilayah Kal-Bar). (Huruswati., dkk, 2012). Sambas yang terletak di bagian utara atau dikenal juga sebagai daerah bagian pantai. Pada awalnya, Sambas merupakan bagian dari Kota Singkawang dan Kabupaten Bengkayang dan mengalami pemekaran pada tahun 2000. Sambas menaungi 17 Kecamatan dengan memiliki 175 Desa. (Huruswati., dkk, 2012). Kabupaten Sambas, terdiri dari beberapa Kecamatan, dan hampir secara seluruh masyarakatnya mayoritas Muslim. (Kementerian Agama, 2017).

Masyarakat Sambas terdiri dari berbagai macam etnis dan etnis yang paling terbesar adalah etnis Melayu. (Arkanudin, t.t.); (Thambun Anyang, 2003). Etnis Melayu mempunyai sejarah 
yang panjang dalam kehidupan manusia, tetapi yang paling penting, etnis Melayu adalah etnis yang suka berlayar, sehingga kata Melayu mempunyai arti berlayar. (Viktor, 2014). Sejarah itu juga, tidak terlepas dari sejarah Melayu yang ada di Sambas, ketika Melayu Sambas masih memeluk agama Hindu, animisme, dinamisme dan kaharingan. Namun, ketika Melayu Sambas memeluk agama Islam, maka Sambas termasuk Paloh terkenal dengan religiusnya dalam beragama. (Yusriadi, 2014); (Adnan, 2015); (Belo, 2016); (Yusriadi, 2019). Agama Islam yang mempunyai peran penting di Sambas, yakni ketika Raden Sulaiman dari Bruneidarussalam menikah dengan mas Ayu Bungsu, anak dari Ratu Sepudak. (Mardiyati, 2011); (Sunandar, 2014); (Sunandar, 2015); (Sunandar, 2015). Akan tetapi, masuknya Islam di Sambas tidak menghilangkan sama sekali kepercayaan masyarakat, lebih-lebih lagi masyarakat Paloh tentang agama budaya lokal nenek moyang.

Masyarakat Paloh merupakan salah satu bagian dari masyarakat Sambas sebagai agama terbesar di zaman pemerintahan ratu sepudak pada waktu itu. (Suhardi dkk., 2020). Namun ketika Islam datang, tidak menyurutkan sama sekali adat, tradisi dan kepercayaan masyarakat Paloh. Daerah Paloh merupakan daerah yang diapit oleh sungai dan laut, sehingga menggambarkan sejarah Melayu Paloh yang bersangkutan. Penelitian ini telah dilakukan oleh Aslan (2019), bahwa nama Melayu diambil dari nama daerah tempat ia tinggal, sehingga Melayu yang tinggal di Paloh, maka dikatakan sebagai Melayu Paloh.

Etnis suku Melayu tidaklah beda dengan etnis-etnis lainnya yang ada di Indonesia, misalnya Sunda. Orang yang masuk Melayu berarti masuk Islam. Simbol ini juga melekat pada etnis Sunda. "Islam teh Sunda, Sundah teh Islam". Islam adalah Sunda, Sunda adalah Islam. (Herawati, 2019). Masuknya Islam di Indonesia dengan membawa pengaruh bagi etnis lainnya, tidak terlepas dari proses Islamisasi.

Islamisasi yang terjadi di Asia Tenggara abad ke 7 M (Lapidus, 1991); (Azra, 2013); (Azra, 2013), maka secara berangsur-angsur masuk ke wilayah Kalimantan Barat, termasuk di wilayah Paloh. Namun, Islamisasi tersebut masih tidak mampu mengubah sebagian kepercayaan masyarakat Paloh tentang sesuatu yang mistik. Kepercayaan ini, sejak dahulu hingga sekarang masih tetap saja bersemi tanpa adanya perubahan. Hanya sedikit saja yang mengalami pergeseran, tetapi hanya pada bagian sesajian dan ritual upacara keagamaan. Bahkan, kepercayaan tersebut bukan saja di percayai oleh masyarakat Paloh tetapi juga dari luar Paloh. Tempat-tempat sakral, yang ada di Paloh, maka tidak boleh dikotori oleh masyarakat Paloh ataupun luar Paloh, karena dapat menyebabkan sesuatu yang tidak diinginkan, baik itu sakit, stress, gila bahkan meninggal dunia, sehingga untuk pergi ke wilayah Paloh terlebih dahulu meminta ijin kepada orang kebenaran atau makhluk halus.

Filosofi Paloh berasal dari peluh, yang mana untuk menembus sungai tersebut, bersusah payah sehingga mengeluarkan peluh (keringat). Di Paloh terdapat tempat yang telah dikeramatkan oleh sebagian masyarakat Paloh atau luar Paloh yang sampai sekarang masih terdapat pantangan dan larangan, yang mana tempat tersebut adalah Batu Bejamban. (Usman (Camat Paloh), 2013). Kepercayaan sebagian masyarakat Paloh yang ada di Batu Bejamban, di tunggu oleh Buaya Putih yang bisa saja menjelma apa saja, misalnya manusia. (Wawancara dengan anggota Pokdarwis, surat, 7 Juni 2017). Konon katanya, bagi masyarakat yang mempunyai hati putih, maka akan dinampakan oleh makhluk halus tentang kenyataan sesungguhnya kota Paloh yang disebut juga sebagai kota kebenaran dan merupakan kota bagi makhlus halus. Bahkan, masyarakat Paloh yang pernah dinampakkan oleh orang kebenaran, ketika pergi berkunjung ke Batu Bejamban, dia melihat kota yang begitu indah dan luar biasa. Dia dibawa kemana-mana di kota makhluk halus tersebut dengan kendaraan mobil yang begitu mewah. Dia mengatakan, keindahan kota kebenaran tidak dapat diungkapkan dengan katakata. (Wawancara dengan salah satu Dukun di Wilayah Paloh, 2017).

Penelitian terdahulu yang mengkaji tentang keagamaan nilai-nilai mistik, pernah dilakukan oleh Langaji, (2016) dan Hermansyah (2010). Langaji mengkaji tentang aliran keagamaan dalam perspektif sosiologis dengan memberikan arti bahwa agama yang aneh dan menyimpang disebut sebagai agama Sempalan. Namun, kajian ini hanya literatur sehingga tidak dapat memberikan sumbangsih yang mendalam tentang aliran agama Sempalan tersebut. Sementara, penelitian yang dilakukan oleh Hermansyah di Kalimantan Barat pada daerah Pontianak dengan judul "Ilmu Gaib di Kalimantan Barat". Hasil penelitian Hermansyah, bahwa IImu adalah orang yang mengetahui tentang bermacam-macam ilmu. Kajian dari disertasinya yang telah menjadi buku dan telah diterbitkannya juga di jurnal, (Hermansyah, 2013) hanya menggambarkan tentang ilmu serapah yang dimiliki oleh orang-orang Pontianak, tetapi kepercayaan ini juga telah mengalami pergeseran. Dari bab hasil penutup disertasi Hermansyah, bahwa suku Melayu yang tinggal di berbagai daerah Kalimantan Barat, memiliki budaya yang berbeda, walaupun ia berasal dari suku Melayu. Perbedaan ini juga menggambarkan tentang perbedaan agama lokal yang dimiliki oleh suku Melayu yang tinggal di Paloh.

Penelitian ini bertujuan untuk menyoroti dinamika keagamaan masyarakat Paloh yang 
masih mempertahankan nilai-nilai agama mistik walaupun saat ini manusia telah mengalami perkembangan teknologi yang luar biasa. Pengaruh masuknya agama Islam dimasa zaman kesultanan Sambas tidak memberikan cukup andil bagi dampak agama Islam tersebut terhadap kepercayaan nenek moyang yang dimiliki oleh masyarakat Paloh.

\section{B. METODE PENELITIAN}

$\mathrm{P}$ enelitian ini menggunakan penelitian lapangan (field research), yang mana penelitian ini adalah untuk mendeskripsikan, menganalisis dari gejala-gejala yang dialami oleh masyarakat, sesuai dengan fokus dalam penelitian. Jenis dalam penelitian ini adalah kualitatif. Maksud dari kualitatif adalah peneliti berusaha untuk memahami keadaan sosial masyarakat atau semua pihak yang dianggap terlibat dalam memberikan informasi penelitian. (Jan Jonker, Bartjan J.W. Pennink dan Sari Wahyuni, 2011).

Penelitian ini dilakukan pada akhir tahun 2019 di Paloh. Paloh merupakan wilayah Kabupaten Sambas yang memiliki beberapa desa, (Aslan, 2019), tetapi yang difokuskan hanya di desa Paloh Merbau.

Data dalam penelitian ini dikumpulkan melalui observasi, wawancara dan dokumentasi. (Silalahi, 2009). Sumber data terdiri dari primer dan sekunder, dengan subjek penelitian adalah dukun Paloh dan beberapa masyarakat Paloh yang mau dimintai keterangan tentang kepercayaan nenek moyang yang masih dimilikinya.

Teknik yang digunakan dalam pengumpulan data terdiri dari observasi (pengamatan), wawancara dan dokumentasi. Metode observasi adalah metode mengamati keagamaan masyarakat di Paloh. (Hancock dkk., 2009); (Imam Suprayogo \& Tobroni, 2001). (M. Djunaidi Ghony \& Fauzan Almansur, 2012). Sementara, wawancara adalah percakapan yang dilakukan oleh peneliti kepada informan untuk mendapatkan keterangan. (Kuntjaraningrat, 2002). Adapun dokumen adalah berupa catatan, transkip buku, dan keterangan lainnya yang berkaitan dengan penelitian. (Arikunto, 2010).

Analisis data dalam penelitian ini menggunakan teori Matthew B. Miles A Michael Huberman (1994), terdiri dari tiga bagian yakni data reduction, data display, dan conclusion drawing/ verification.

\section{HASIL DAN PEMBAHASAN}

$\mathrm{D}$ inamika keagamaan adalah gambaran tentang perjalanan kehidupan masyarakat dalam beragama. (Ridwan, 2016). Agama yang dimiliki manusia mempunyai otoritas masing-masing yang memberikan simbol ma- nusia dalam keyakinan agama yang dimiliki. (Rumadi, 2012). Penelitian yang dilakukan oleh Rota \& Krüger, (2019), P, (1944) tentang dinamika keagamaan yang mengalami pergeserah seiring dengan perubahan sosial yang dialami masyarakat, termasuk terbentuknya komunitas baru dalam keyakinan beragama di era informasi saat ini.

Agama dari kepercayaan masyarakat tidak terlepas dari simbol. (Geertz, 1973) (Cassirer, 1994) (Mujiburrahman, 2013). Dalam agama Islam, simbol adalah segala sesuatu yang berkaitan dengan agama Islam, baik itu pakaian, dalam melaksanakan ibadah shalat maupun ritual dalam pelaksanaan haji. (Mujiburrahman, 2008). Berkaitan dengan itu pula, masyarakat Paloh dalam menjalankan agama Islam seperti masyarakat pada umum lainnya, tetapi kepercayaan tersebut mengalami perpaduan tentang kepercayaan yang berkaitan dengan dunia mistik.

Perubahan yang terus terjadi, seiring dengan perkembangan teknologi, tetapi dinamika keagamaan dari otorititas kepercayaan sebagian besar masyarakat Paloh adalah tentang sesuatu yang mistik.

Mistik adalah sesuatu peninggalan nenek moyang untuk mempercayai sesuatu yang gaib. (Malefijt, 1968). Sesuatu yang mempunyai nilai keramat yang dapat membentuk perilaku manusia dalam beragama. (Anggraini, 2013); (Humaeni, 2012). Kepercayaan masyarakat dalam beragama dengan nilai-nilai mistik memberikan adanya perbedaan budaya lokal agama yang dipercayai oleh masyarakat.

Menurut Roland Robertson, ed (1995), empat tipe dalam beragama yang dimiliki masyarakat, terdiri dari tingkat rahasia, pribadi, kelompok dan seluruh masyarakat, sama-sama juga dimiliki oleh masyarakat Paloh. Kepercayaan itu berawal sejak kejadian misteri hilangnya pesawat TNI AU di wilayah negeri Paloh pada tahun 1970, yang mana berdasarkan penerawangan para ahli spiritual bahwa orang-orang yang ada di pesawat tersebut tidak meninggal dunia, tetapi diselamatkan oleh makhluk halus di Paloh. Semenjak kejadian itu, makhluk halus sering menampakkan keberadaanya termasuk kota besar yang ada di Paloh yang dimiliki oleh makhluk halus. Padahal, daerah Paloh merupakan hutan belantara yang kiri kanannya adalah sungai, tetapi bagi masyarakat yang dilihatkan oleh makhluk halus, Paloh merupakan kota terbesar bagi makhluk halus. Kemudian, konon katanya banyak perawan-perawan yang hilang dan anak-anak di Paloh ketika bermain dengan temannya, yang mana makhluk halus yang bisa menyerupai manusia sehingga telah membawa anak-anak tersebut di kotanya. Bahkan, ketika sudah dibawa ke kota Paloh, maka sangat tipis sekali untuk pergi lagi ke dunia nyata. (Mahjuni, surat, 2017); (Indonesia!, t.t.) (Koten, t.t.) (Hafield, t.t.). 
Pernah suatu ketika pada tahun 2000-an masyarakat Paloh dari Merbau bercerita pernah dibawa oleh orang kebenaran di kota Paloh. Bahkan, dia juga diajak untuk menikah dengan orang kebenaran dengan syarat tidak lagi balik ke dunia. Namun, persyaratan tersebut tidak disetujuinya sehingga ia dilepaskan oleh orang kebenaran dan balik ke dunia nyata.

Sampai saat ini, daerah Paloh dianggap oleh sebagian masyarakat Paloh sebagai "Kota Kebenaran" atau tempat tinggalnya makhluk halus. (Masyarakat Paloh, surat, 2017). Menurut Dukun Paloh, sekaligus mengaku sebagai pemegang juru kunci pada kota kebenaran tersebut, yang mendapat informasi melalui mimpi dari penunggu Paloh, bahwa Paloh ditempat tinggali oleh orang kebenaran dari anak cucu zuriat "Patek Gole Lender". Datangnya "Patek Gole Lender" ke Paloh bertujuan untuk menyerang Majapahit, tetapi la tidak mampu untuk menyerangnya sehingga pada saat la balik ke Malaka, melanggar Batu Bejamban yang ada di Paloh. Diantara zuriat dari "Patek Gole Lender" yang menjadi orang kebenaran sebagai penunggu Paloh sampai sekarang ini yang menjadi kepercayaan masyarakat Paloh adalah "Datok Panglime Hitam, Datok Panglima Cantek, Datok Tauhid, Datok Meraje Lela, Datuk Adul, Datuk Raye Pander, Datuk Lidah Bulu, Putri Mayang Rampai, Putri Melati”. Penunggu dari penjaga Paloh ini, bisa saja dipanggil sewaktuwaktu, jika masyarakat Paloh memerlukan pertolongan. Datok yang paling berkuasa diantara Datok yang lainnya adalah "Datok Meraje Lela". Sementara, "Datok Buluh Bulu" tidak boleh dilanggar pantangannya, karena kalau ia menyumpah kita, maka ucapannya "makbol"/terwujud. (Wawancara dengan Dukun di Wilayah Paloh, surat, 2017). Cerita-cerita mitos ini banyak sekali terdapat perbedaannya, yang sampai sekarang masih belum ditemukan sumber keaslian dari keontetikan cerita ini, tetapi dari sekian banyak cerita dari masyarakat Paloh, bahwa daerah Paloh adalah daerah tempat tinggal orang kebenaran.

Tempat yang telah dikeramatkan oleh sebagian masyarakat Paloh dan luar Paloh yang mengandung nilai-nilai kemistikan yang telah terkenal dimana-mana adalah Batu Bejamban. Konon katanya, sejak terjadinya peperangan yang begitu besar di Paloh pada abad ke 15 telah melibatkan orang halus yang berasal dari Jawa, Bruneidarussalam dan Pahang sehingga peperangan yang begitu sengit, mengakibatkan datangnya empat Dewa Kayangan yang masih adik beradik dan mereka turun ke bumi untuk mendamaikan peperangan tersebut. Keempat Dewa tersebut mempunyai tugasnya masingmasing; "Dewa yang tertua menjaga harta yang ada di atas bukit, Dewa yang tengah menjaga daerah rawa, Dewa yang muda menjaga di pinggir sungai, sedangkan Dewa yang bungsu menjaga di tengah-tengah sungai”. Sejak penjagaan tersebut, maka tadi yang pada awalnya daerah Paloh tidak bisa diamankan, telah bisa diamankan oleh para Dewa pada waktu itu. Agar kejadian itu tidak terulang kembali, maka keempat Dewa membuat peraturan yang tegas bahwa "bagi siapa yang melakukan peperangan atau bersikap tidak benar akan diberi hukuman seberat-beratnya" yang bukan saja diperuntukkan untuk orang halus yang jahat tetapi untuk manusia, baik yang tinggal di Paloh maupun masyarakat yang tinggal di luar Paloh. (Indonesia!, t.t.)

Selang beberapa tahun kemudian, orangorang Kalimantan telah melakukan hubungan dagang dengan daerah Pulau Jawa, sehingga perdagangan tersebut telah banyak menguntungkan kedua daerah tersebut, lebih-lebih lagi masyarakat Jawa yang mendapatkan hasil tukaran barang berupa emas, intan dan barang tambang lainnya. Atas hasil tukaran tersebut, sehingga niat dari raja Jawa sudah berubah sehingga raja Jawa mengutus dua buah kapal untuk pergi ke Kalimantan untuk mengambil kekayaan yang dimiliki oleh Pulau Kalimantan tersebut. Sejak kejadian itu sampai sekarang, nama Borneo diambil dari kata berlian atau "tanah yang banyak menyimpan harta kekayaan". Kapal layar yang pertama dinakhodai oleh Si Muda dan Si Bungsu, sedangkan kapal yang kedua dinakhodai oleh Raden Martil dan Pangeran Marta dengan masing-masing membawa pengawal dan juragan yang setia. Akan tetapi, pelayaran mereka mengalami hambatan karena badai laut yang begitu besar sehingga mereka terdampar di wilayah yang berbeda-beda. Kapal layar yang pertama terdampar di Kalimantan bagian selatan, sementara kapal layar yang kedua terdampar di Paloh dan melanggar batu di tengah-tengah sungai yang saat ini dikenal dengan "Batu Bejamban". Atas kejadian yang dilakukan oleh Si Bungsu dan Si Muda, maka Dewa Bungsu marah kepada mereka dan atas kejadian itu juga Dewa Bungsu memberitahukan kepada ketiga Dewa lainnya, sehingga mereka dikenakan adat. Pantang larang yang diberikan kepada mereka oleh para Dewa, bahwa Si Bungsu tidak boleh naik ke darat dan Si Muda boleh naik ke darat, karena Si Bungsu masih belum menguasai ilmu kebatinan, masih belum bisa untuk berkomunikasi dengan baik kepada keempat para Dewa tersebut dan tingkah lakunya masih dianggap kurang baik. Sedangkan, Si Muda sudah mumpuni menguasai ilmu kebatinan yang bisa melihat para Dewa. Sewaktu, Si Muda di bawa ke kota mahluk halus dengan begitu lama membuat Si Bungsu berprasangka buruk terhadap kakaknya, apakah masih hidup atau sudah meninggal dunia sehingga ia berniat untuk naik ke darat tetapi ia tidak mampu untuk menembus kota makhluk halus tersebut yang dikenal sebagai "Kota Kebenaran atau Kota 
Bunian". Padahal, kakaknya yang hidup di kota Bunian telah bergelimang dengan kemewahan dan kenikmatan, karena Dewa sangat memberikan pelayanan yang khusus untuk Si Muda ini. Selain itu juga, ilmu kebatinan yang dimiliki Si Muda, maka Dewa sudah berpikir untuk meninggalkan Paloh dan menjadikan Si Muda sebagai raja untuk menjaga Paloh nantinya. Pelantikan kepada Si Muda oleh Dewa kayangan untuk menjadi raja penjaga Paloh, terlebih dahulu Para Dewa menanyakan kesanggupannya kepada Si Muda yang mana isi perjanjiannya adalah "barang siapa yang menjadi penguasa kota Paloh hendaknya menjadi pemimpin yang benar, jujur dan tidak melanggar peraturan yang telah dibuat oleh keempat Dewa sebelumnya. Jika hal itu dilanggar, maka akan turun hukuman yang setimpal menimpa kota Paloh". Hal inilah yang menjadikan kota Paloh sebagai kota kebenaran, yang artinya sebagai kebenaran dalam tingkah laku, tutur kata, dan bijak dalam mengambil keputusan. Setelah kesepakatan itu dibuat antara Si Muda dan Dewa Kayangan, maka Si Muda dilantik sebagai raja penguasa Paloh, sehingga raja muda memberi kerajaannya dengan nama Batu Bejamban. Menurut (Sastranagari, 2017), penghuni Paloh yang disebut sebagai kaum Bunian mempunyai bentuk yang hampir sama dengan manusia, tetapi perbedaannya terletak pada wajahnya. Kaum bunian tidak memiliki aris antara hidug dan bibir. Alisnya menyatu sehingga perbedaan ini sangat sungguh menyeramkan.

Kemudian, nasib yang dialami oleh Si Bungsu yang bertolak belakang dengan nasib kakaknya, yang mana Si bungsu yang berkeingian untuk balik ke Jawa tetapi ia tidak bisa untuk balik dengan beberapa masalah, seperti pertanggungjawaban kepada raja Jawa dan ia tidak bisa sepenuhnya untuk mengemudikan kapal layar. Semenjak Si Bungsu tinggal di kapal layar, maka ia sering melanggar larangan yang telah dibuat oleh Dewa, seperti "mengganggu kehidupan hewan di hutan, tumbuh-tumbuhan dan sering kali mengotori aliran sungai dengan sisa-sisa makanan yang diramunya". Oleh karena itu, sebagai balasannya, makhluk halus sering mendatangi Si Bungsu untuk memberi peringatan kepadanya sehingga ia sakit secara tiba-tiba dan sembuh juga secara tiba-tiba. (Indonesia!, t.t.).

Segala kemegahan dari Paloh yang telah dibangun oleh raja muda sebuah kota kerajaan yang begitu megah, tetapi diwaktu lain ia sudah mulai merasakan kehilangan sesuatu yang terjadi pada dirinya. Karena, pada waktu Si Muda pergi ke kota Bunian para Dewa, maka terlebih dahulu ingatannya dihapus oleh Dewa agar sejarah masa lalunya terlupakan. Akan tetapi ingatan tersebut hanya seketika, sehingga ia baru ingat dengan adiknya yang menemani berlayar pada waktu ingin pergi ke Kalimantan. Raja muda yang mempunyai ilmu kebatinan yang tinggi dan apalagi mendapat kesaktian dari para Dewa, sehingga ia melihat sosok tubuh kerdil yang berada di kapal layar di daearah sungai Paloh, yang mana sosok tubuh tersebut adalah adiknya. Oleh karena itu, raja Muda menyuruh prajuritnya untuk menjemput adiknya dan dibawa ke kerajaan Bunian. Adiknya yang telah lama tidak berjumpa dengan kakaknya sehingga tidak lagi mengenali kakaknya yang telah menjadi raja Bunian tersebut. Kemudian, kakaknya memberitahukan kepada adiknya bahwa ia adalah Si Muda atau kakaknya, sehingga Si Bungsu memeluk erat kakaknya karena berpisah sangat begitu lama. Selang lama kemudian, kehidupan yang begitu mewah yang dirasakan oleh Si Bungsu, sehingga lama kelamaan Si Bungsu mengutarakan hatinya untuk mengajak kakaknya bersama-sama pulang di Jawa, tetapi kakaknya menolak karena kakaknya telah membuat perjanjian dengan Para Dewa sebelumnya. Akhirnya, Si Bungsu menyadari hal tersebut dan balik sendiri ke Jawa dengan dibekli uang emas, makanan secukupnya oleh kakaknya dan diawasi oleh pengawal kerajaan hingga ke laut Jawa.

Sepulang adiknya, maka raja Muda semakin memperbesar wilayah kerajaannya di Paloh dan membuat jalan perdagangan yang dikenal sebagai "Tanah Merah". Untuk menjaga keamanan di Paloh, apalagi Si Bungsu yang telah balik ke Jawa, maka pasti akan memberitahukan kekayaan yang ada di Batu Bejamban sehingga yang nantinya akan menimbulkan pertikaian banyak orang nantinya. Agar kejadian itu tidak terjadi, maka raja Muda meminta pertolongan kepada Dewa Kayangan untuk mengirim utusan sebagai menjaga kekayaan kerajaannya. Permintaan tersebut dipenuhi oleh Dewa Kayangan dan akhirnya Dewa mengutus "Mustika Bintang" untuk menjaga harta kekayaan istana yang tersimpan di dalam gua. Harta yang begitu banyak, sehingga dapat menerangi kerajaan raja Muda pada malam harinya. Kemudian, Para Dewa mengutus yang lainnya untuk menjaga harta tersebut yang bernama Mayangsari. Dia diperintahkan untuk memegang kunci gua tempat penyimpanan harta kekayaan di Batu Bejamban. Untuk memperluas kerajaan, maka raja Muda membina hubungan persaudaraan dengan Kesultanan Sambas yang mana pada waktu itu masih dipimpin oleh Bujang Nadi dan Dare Nandung. Agar hubungan semakin akrab, maka raja Muda, mengadakan pesta kerajaan di Semenanjung Borneo. Kerajaan Sambas di wakili oleh Raden Sandi dan Raden Sambir, Kesultanan Brunei diwakili oleh Sultan Tajudin dan kerajaan Pontianak. Perayaan ini juga untuk menetapkan simbol kerajaan sebagai lambang perekat pemersatu, yakni warna kuning yang melambangkan Kesultanan sambas, warna merah melambangkan Kerajaan Brunei dan Pontianak dan warna putih melambangkan Kerajaan Batu Bejamban. Setelah diadakan 
perayaan tersebut, tersiar kabar bahwa daerah Sambas diserang oleh makhluk yang begitu kejam yang berasal dari keturunan jin. Kekejaman tersebut terlihat dari ia menyuruh wanita hamil untuk mendorong perahu ke dermaga, wanita perawan menjadi santapan setiap hari dan bayi dijadikan makanan untuk setiap harinya. Jin tersebut dikenal sebagai Tan Unggal. Oleh karena itu, raja muda mengutus orang kepercayaannya untuk membasmi Tan Unggal dan prajuritnya yang bernama Tan, (tahan banting) sehingga Tan Unggal dan prajuritnya dibunuh oleh Tan dari utusan raja muda. (Mustansyir, 2016, hlm. 33).

Dalam "kitab Negara Kertagama karya Prapanca", sebelum Tan Unggal memerintah Sambas, maka terlebih dahulu diperintah oleh "Nek Riuh". Setelah Nek Riuh meninggal, maka kemudian diperintah oleh Tan Unggal. Pada masa ini, pemerintahan yang begitu kejam pada masyarakat Sambas dari Tan Unggal sehingga Tan Unggal dibunuh oleh utusan raja Muda Paloh dan atas kekejamannya, sehingga hampir puluhan tahun masyarakat Sambas tidak mau lagi untuk mengangkat raja. Dengan adanya kekosongan kerajaan tersebut, sehingga pada awal abad ke-16 M (1530 M), Sambas kedatangan Bangsawan dari Jawa sekitar 500 orang. Mereka melarikan diri dikarenakan dari masalah politik di daerahnya. Kedatangan mereka ke Sambas tidak pernah menimbulkan konflik bagi Suku Melayu yang tinggal di Sambas. Mereka tinggal lama di sungai Sambas yang berada di Kota Lama, sehingga mereka mendirikan sebuah Panembahan atau Kerajaan Hindu, kemudian dikenal sebagai "Panembahan Sambas". Pada masa pemerintahan awal Kerajaan Sambas ini, tidak diketahui namanya. Kemudian setelah raja pertama wafat, maka digantikan oleh anaknya yang bernama Ratu Timbang Paseban dan kemudian digantikan oleh adiknya yang bernama Ratu Sapudak. Disaat Ratu Sapudak memimpin kerajaan Sambas, kemudian kedatangan tamu dari Sultan Sarawak ke 1 atau disebut juga Sultan Tengah sehingga sampai menetap di Sungai Sambas di daerah Kembayat Sri Negara. Anak laki-laki Sultan Sarawak yang bernama Sulaiman, terpikat dengan hati dari anak gadis raja Sapudak yang bernama Mas Ayu Bungsu, sehingga Sulaiman berubah menjadi Raden Sulaiman. (Murtadlo, 2014).

Pada awalnya, di masa Sambas dikuasai oleh kekuasaan tradisional, Sambas di perintah oleh kerajaan Majapahit, yang mana pemerintahannya menyebar di daerah Paloh, "Jawai" (Hade Irma Wati., dkk, 2015), Kota Lama dan wilayahwilayah lainnya. Kota Paloh dipimpin oleh Raden Janur pada abad ke 14, kemudian digantikan oleh Wiqrama Whardana dan dilanjutkan lagi oleh Raja Gipang. Pada masa kekuasaan Raja Gipang di Paloh, maka Raja ini membuat pangkalan pendaratan untuk pasukan kerajaan Majapahit, yang berada di Jawai, Paloh yang dimulai pada tahun $1350 \mathrm{M}$ dan mengalami perubahan secara besar-besaran pada tahun 1364 M. Di awal ini juga, Kota Lama dan Kota Sebangun menjadi pusat kerajaan Ratu Sepudak. (Sunandar, 2015c, hlm. 15).

Rentetan-rentetan sejarah kerajaan Sambas yang berawal dari kerajaan yang kejam, kemudian digantikan oleh raja-raja lainnya sampai ke daerah Paloh, tetapi raja Muda yang berasal dari Jawa dan sudah menjadi orang kebenaran sehingga sampai sekarang tidak pernah tergantikan oleh raja-raja lainnya dan juga sampai sekarang masih dipercayai masih hidup dan menjaga Paloh. Konon katanya, daerah Paloh yang telah menetapkan simbol berwarna putih, sehingga masyarakat yang dinampakkan oleh kaum Bunian telah melihat sesosok buah putih atau "jallu" di daerah Batu Bejamban. Dunia misteri di kota Paloh hanya bisa dilihat dari orang-orang tertentu yang mendapatkan izin dari orang kebenaran. Sewaktu kejadian tragedi Sambas antara Suku Melayu dan Madura pada tahun 1999, begitu banyak masyarakat Paloh dan juga Sambas pergi ke Batu Bejamban untuk meminta bantuan kepada orang kebenaran dan pergi ke kerajaan Sambas untuk meminta bantuan kepada kerajaan Sambas. Bahkan, pada waktu itu, foto Kesultanan Sambas menjadi jimat kebal yang dibungkus dengan simbol kain putih kemudian dibungkus lagi dengan kain kuning dan jimat tersebut diberi khadam (bacaan) oleh seorang Dukun atau orang yang mempunyai IImu. Kepercayaan foto Kesultanan Sambas semakin kuat ketika ada masyarakat yang menaruh foto Sultan Sambas dan pada waktu itu terjadi kebakaran dengan menghabiskan beberara rumah, tetapi rumahnya tidak terbakar, sehingga dia beranggapan rumahnya dijaga oleh Sultan.

Sampai saat ini, kepercayaan tentang masalah mistik di Paloh masih tetap saja ada, sehingga untuk pergi ke Paloh, maka terlebih dahulu mengucapkan salam kepada penjaga Paloh dan jika tidak permisi maka ditakutkan terjadi sesuatu yang tidak diinginkan. Untuk melihat kebenaran tersebut, sehingga pernah juga orang yang mempunyai indera keenam menerawang dengan mata batin, dan mengatakan bahwa Batu Bejamban merupakan kota yang terbesar di Kalimantan Barat. Pelabuhan yang terbesarnya, ada di Kota Lama. Cerita tersebut didukung juga oleh salah satu mimpi masyarakat Paloh yang pernah mendengar cerita orang tua dahulu, sewaktu ia masih kecil bahwa pernah, pada zaman Jepang melintasi Batu Bejamban pada hari malam. Orang Jepang tersebut, melihat bahwa Batu Bejamban adalah Kota yang besar, hampir sama dengan Kota di Jepang, kata orang Jepang sendiri. Pada saat dia melintasi Batu Bejamban, 
dia memberi tanda dari sungai tersebut. Namun, pada waktu siang, orang Jepang kembali lagi, ternyata hanyalah hutan belantara. Padahal, tanda yang diberinya masih ada. (Masyarakat Paloh, surat, 2017). Kejadian-kejadian ini yang berawal dari pesawat yang hilang, kemudian adanya penampakan kota yang modern di Paloh sampai saat ini masih dipercayai oleh sebagian masyarakat Paloh dan luar Paloh.

Batu Bejamban dan daerah Paloh lainnya dianggap oleh sebagian masyarakat Paloh sebagai tempat tinggal makhluk halus yang mempunyai nilai keramat. Hampir setiap minggu, selalu ada saja yang mengunjunginya, yang bukan saja dari Suku Melayu yang tinggal di Paloh/luar Paloh, tetapi berasal juga dari Suku Cina yang tinggal di berbagai daerah, termasuk Jakarta. Suku Cina, hampir setiap tahun, datang ke Batu Bejamban untuk membayar niat. Karena, pada saat meminta di Batu Bejamban niat dari Suku Cina terkabul, sehingga Batu Bejamban dibangun oleh Cina yang berasal dari Jakarta. Sementara, bagi Suku Melayu pergi ke Batu Bejamban, tergantung juga niatnya. Ada yang minta carikan jodoh, mengobati berbagai macam penyakit dan dalam hal kegiatan lainnya.

Banyaknya Suku Cina yang datang di Batu Bejamban untuk meminta kekayaan dengan cara "menyemah" dan menggunakan sesajian babi untuk memanggil Jin Cina yang bertolak belakang dengan penunggu Batu Bejamban, sehingga penunggu dari Batu Bejamban, merasa dikotori oleh Suku Cina, dan akhirnya penunggu dari Batu Bejamban telah meninggalkan Batu Bejamban dan balik ke Istana Sambas. Dan ada juga Dukun yang lainnya mengatakan bahwa balik ke kayangan. Mereka akan datang lagi ke Batu Bejamban, kalau dipanggil oleh Dukun yang mengetahui cara memanggilnya. Bagi masyarakat yang mengunjungi Batu Bejamban yang mempunyai nilai kejujuran, kebenaran, maka barang sakti yang ada di Batu Bejamban akan menghampiri masyarakat tersebut, tanpa perlu lagi untuk memintanya. Sementara, orang yang pergi ke Batu Bejamban hanya orang yang serakah dan meminta barang yang bermacammacam sehingga tidak akan diberinya.

Menurut Dukun Besar Paloh, bahwa ia telah diberi oleh orang kebenaran yang namanya "tongkat sakti" dan "besi kuning". "Tongkat sakti", kegunaannya untuk pergi kemana-mana, agar selalu dilindungi dan "besi kuning" untuk kebal. Sebelum mendapatkan barang sakti di Batu Bejamban, la banyak menggunakan ilmu hitam. Sementara ini, karena sudah mendapatkan ilmu di Paloh yang disebutnya sebagai ilmu putih sehingga ilmu hitam tidak lagi digunakan. IImu putih dianggapnya adalah untuk menolong orang. Oleh karena itu, untuk mengobati orang yang sakit, maka Dukun Paloh terlebih dahulu pergi ke Batu Bejamban untuk meminta tolong dan mengadakan beberapa ritual. Banyaknya peminat dari "tongkat sakti" yang sampai dari Brunei untuk membelinya, tetapi karena kabar beritanya tidak ada sehingga dijual kepada Polisi di Sambas. (Wawancara dengan Dukun di Wilayah Paloh, surat, 2017).

Kemudian, pada saat kantor Polsek dibangun, tetapi tidak terlebih dahulu meminta izin kepada penjaga Paloh sehingga tidak ada polisi yang berani untuk menidurinya, dan akhirnya dipanggil Dukun besar Paloh untuk meminta izin kepada orang kebenaran terlebih dahulu. Pada saat salah satu anggota polisi kehilangan uang, maka kepada Dukun Paloh, polisi tersebut meminta bantuan dan akhirnya barang yang hilang ditemukan. Pada saat adanya rencana pembangunan jalan dari Paloh Merbau menuju Temajuk, maka ia terlebih dahulu dipanggil untuk meminta izin kepada penunggu Paloh. Menurutnya, untuk meminta izin kepada penjaga Paloh atas akan dibangunnya jalan darat menuju Merbau-Temajuk, maka ia menggunakan sesajian yang diberikan kepada makhluk halus sebagai ungkapan permisi, yang terdiri dari bermacam-macam "bunga, rateh, beras kuning, dan kak gontal". Pada saat ia memberikan sesajian tidak menggunakan ayam, karena niat pertamanya tidak dengan menggunakan ayam, tetapi menggunakan "hidung mak sinar". Makna dari "Hidung Mak Sinar" sebenarnya bacaan dari "Roh Ku, Cahayeku, Dagingku dengan Anginku, Nyawaku Akiku, Sifatku Kakiku, Jasadku Tanahku. Dari Tanah ke Tanah dari Angin ke Angin". (Wawancara dengan Dukun di Wilayah Paloh, surat, 2017).

Sejak dahulu sampai sekarang, daerah Paloh masih tetap saja Paloh yang masih saja tersimpan dunia mistik sehingga walaupun tempat makhluk halus sudah dikotori oleh Suku Cina, tetapi masih saja kalau mau pergi ke Paloh tidak boleh berkata sumbar, baik di darat dan juga di laut. Jika sumbar, maka akan menjadi kualat dari penjaga Kota Paloh. Karena, kalau masih saja kita melanggar pantangan dan larangannya, maka akan mengakibatkan macammacam kejadian yang nantinya akan menimpa diri kita sendiri. Mungkin, kalau kita balik dari Paloh, nanti kepala kita bisa menjadi gundul (botak). Oleh karena itu, kalau mau ke Paloh memang harus permisi dulu. Kalau ada apa-apa, harus minta maaf. Daerah Paloh merupakan daerah kebenaran, kejujuran, yang masyarakatnya tidak boleh berbuat macam-macam atau melanggar pantangan. Masyarakat pernah memancing ikan di sungai Paloh dengan mengatakan banyak ikan di Paloh, maka ikan tersebut berubah menjadi kayu dan tidak lagi menjadi ikan. (Wawancara dengan Dukun di Wilayah Paloh, surat, 2017).

Hal ini juga telah dibenarkan juga oleh salah satu polisi yang bertugas di Paloh, yang mana dia telah diberi peringatan oleh Dukun Paloh agar tidak boleh berkata asal-asal karena ada 
pantangan dan larangan di kawasan Paloh. Lebih lanjut lagi, polisi tersebut menceritakan pengalamannya pada tahun 2006, bahwa sewaktu ia menjaga di Pos Perbatasan Temajuk dan balik dari Temajuk melalui jalan pantai dengan menggunakan sepeda motor dan dalam pikirannya agak sumbar sedikit dengan mengatakan, "bagusnya jalan pantai yang telah dilaluinya". Setelah beberapa menit kemudian, ban motornya bocor, sehingga ia terpaksa menyerat sepeda motornya. Sejak kejadian tersebut, sampai saat ini, ia tidak lagi pernah mengucapkan kata-kata yang asal-asal, karena nantinya akan membawa mala petaka bagi dirinya. (Polisi, surat, 2017).

Paloh yang terkenal dengan kemistikannya terhadap dunia gaib, maka masyarakat untuk berinteraksi dengan dunia gaib melalui perantara seorang dukun, sebagaimana pendapat Paul Reddisha, Penny Toka, and Radek Kundta (2016) dan Koentjaraningrat (2014), tentang peran dukun bagi masyarakat dalam beragama dalam melaksanakan ritual keagamaan.

Dengan demikian, dari beberapa sejarah tentang kepercayaan masyarakat Paloh dalam beragama menggambarkan tentang dinama keagamaan masyarakat Paloh dalam beragama. Kepercayaan yang masih kental terhadap nilai nenek moyang hampir secara keseluruhan pada masyarakat Paloh telah mematahkan teori Rumadi, (2012) tentang otoritas keagamaan setiap individu dan Rota \& Krüger, (2019), tentang komunitas baru masyarakat dalam beragama dari dampak perkembangan teknologi.

Masyarakat Paloh secara global telah mengalami perubahan sebagaimana daerah yang sudah maju, tetapi nilai-nilai dari kisah cerita nenek moyang tentang Paloh sebagai kota kebenaran, kota larangan, kota hukuman bagi masyarakat Paloh dan luar Paloh yang berniat jahat terhadap Paloh tersebut. Simbol kemistikan dan nilai kepercayaan tidak mampu menggeser dari kepercayaan masyarakat Paloh terhadap sesuatu yang msitik di era informasi saat ini.
Daerah Paloh seiring dengan waktu mengalami perubahan yang luar biasa, tetapi tidak mampu mengubah dinamika keagamaan masyarakat Paloh secara keseluruhan.

Sistem kepercayaan masyarakat Paloh merupakan sebuah adat, tradisi yang perlu dilestarikan sekaligus untuk mengajarkan kepada generasi milinel bahwa mayoritas suku Melayu adalah suku yang bermartabat sehingga katakata, tingkah laku yang tidak sesuai dengan nilainilai agama, mendapat ancaran dari orang kebenaran terhadap masyarakat di Paloh. Intinya, untuk pergi ke Paloh harus sesuai dengan ucapan dan perkataan sehingga nenek moyang yang mengajarkan nilai kebaikan kepada keturunannya dengan nilai mistik, pada hakikatnya adalah untuk mengajarkan kebaikan.

\section{E. UCAPAN TERIMA KASIH}

$\mathrm{T}$ erima kasih kepada masyarakat Paloh yang terdiri dari delapa desa, khususnya di Merbau, Temajuk, Matang Danau, Guntung, Matang Putus, Kalimantan dan Arung Parak. Terima kasih juga atas masukan dan kritikan kepada dosen pembimbing, yakni Mujiburrahman (Rektor UIN Antasar Banjarmasin) dan Wahyudin yang bersedia memberikan masukan dan kritikan dari artikel ini yang merupakan bagian terkecil dari pembahasan disertasi penulis.

\section{KESIMPULAN}

$\mathrm{D}$ inamika keagamaan dari dampak perubahan yang dialami masyarakat seiring dengan perkembangan teknologi, tidak mampu mengubah kepercayaan masyarakat Paloh terhadap sesuatu yang mistik.

\section{DAFTAR PUSTAKA}

Adnan. (2015). Urgensitas Pendidikan Islami Dalam Membangun Rakyat Sambas di Era Masyarakat Ekonomi Asean (MEA) dalam Proceeding of 1st International Conference on ASEAN Economic Community in Borneo Region. Kalimetro Intelegensia. 
Agus Salim. (2014). Perubahan Sosial: Sketsa Teori dan Refleksi Metodologi Kasus Indonesia (Cetakan Ke-2). Tiara Wacana Yogya.

Agustono, I. (2016). Dinamika Politik Islam Semenanjung Arab 1800-1930 M dan Pengaruh Berdirinya Kerajaan Arab Saudi Modern terhadap Praktik Keagamaan. Maraji: Jurnal Ilmu Keislaman, 3(1), 80-105. https://doi.org/10.36835/maraji.v3i1.63

Anggraini, I. (2013). Sikap Masyarakat Surabaya Terhadap Pesan Mistik Dalam Program Acara Dua Dunia Di Trans 7. E-Komunikasi, 1(1), 1-12.

Arikunto, S. (2010). Prosedur Penelitian: Suatu Pendekatan Praktek. Rineka Cipta.

Arkanudin. (t.t.). Pluralisme Suku Dan Agama Di KALBAR [(Laporan Hasil Penelitian Pusat Penelitian FISIP dan Program Magister IImu Sosial, Untan Pontianak)].

Aslan. (2019). Peran Pola Asuh Orangtua di Era Digital. Jurnal Studi Insania, 7(1), 20-34.

Aslan. (2019). Pergeseran Nilai Di Masyarakat Perbatasan (Studi tentang Pendidikan dan Perubahan Sosial di Desa Temajuk Kalimantan Barat) [Disertasi, UIN Antasari Banjarmasin]. https://idr.uin-antasari.ac.id/10997/

Aslan, \& Hifza. (2020). The Community Of Temajuk Border Education Values Paradigm On The School. International Journal of Humanities, Religion and Social Science, 4(1), 13-20.

Azra, A. (2013). Islamisasi Jawa. Studi Islamika, 20(1), 169-177.

Belo, M. I. O. M. (2016). Islam di Kesultanan Sambas Kalimantan Barat (1600-1732) [Skripsi tidak diterbitkan]. Sanata Dharma.

Cassirer, E. (1994). An Essay on Man, An Introduction to Philosophy of Human Culture. University Press.

Daud, A. (1997). Islam dan Masyarakat Banjar: Deskripsi dan Analisa Kebudayaan Banjar. PT. Raja Grafindo Persada.

Geertz, C. (1973). The Interpretation Of Cultures. Basic Books, Inc., Publisher.

Hade Irma Wati., dkk. (2015). Potensi Obyek Dan Daya Tarik Pulau Pontianak Sebagai Wisata Alam Di Kecamatan Jawai Selatan Kabupaten SambaS. 3(1), 65-73.

Hafield, I. S. (t.t.). Legenda Mistis Negeri Paloh Kerajaan Gaib di Kalimantan | SegiEmpat. Diambil 13 Januari 2019, dari https://segiempat.com/aneh-unik/mistis/legenda-negeri-paloh/

Hancock, B., Ockleford, E., \& Windridge, K. (2009). An Introduction to Qualitative Research. University of Sheffield regent Court.

Herawati, E. (2019). Budaya, Agama, dan Makna Volunterisme Bagi Kader Warga Peduli Aids di Kota Bandung. Jurnal Antropologi: Isu-Isu Sosial Budaya, 21(02), 132-141.

Hermansyah. (2010). Ilmu Gaib di Kalimatan Barat. KPG (Kepustakaan Populer Gramedia bekerjasama dengan Ecole Francaise d'Extreme-Orient, STAIN Pontianak, KITLV.

Hermansyah. (2013). Islam Dan Toleransi Beragama Dalam Masyarakat Muslim Kanayatn Dayak DI Kalimantan Barat. Islamica, 7(2), 340-359.

Humaeni, A. (2012). Makna Kultural Mitos dalam Budaya Masyarakat Banten. Antropologi Indonesia, 33(3), 159-179.

Huruswati., dkk, I. (2012). Evaluasi Program Pembangunan Kesejahteraan Sosial Di Desa Perbatasan-Kalimantan Barat 2012. P3KS Press.

Imam Suprayogo \& Tobroni. (2001). Metodologi Penelitian Sosial-Agama. Remaja Rosdakarya.

Indonesia!, I.-S. B. (t.t.). Misteri dan Keunikan Suku Gaib Paloh dari Sambas Kalimantan Barat. Diambil 13 Januari 2019, dari http://indoborneonatural.blogspot.com/2014/07/misteri-dankeunikan-suku-gaib-paloh.html

Jan Jonker, Bartjan J.W. Pennink dan Sari Wahyuni. (2011). Metodologi Penelitian. Salemba Empat.

Kementerian Agama. (2017). Kementerian Agama Kabupaten Sambas.

Koentjaraningrat. (2014). Pengantar IImu Antropologi. Rineka Cipta.

Koten, T. (t.t.). Inilah Kerajaan Siluman, Bangsa Paloh, di Hutan Belantara Ka... Diambil 13 Januari 2019, dari http://www.netralnews.com/news/rsn/read/115943/inilah-kerajaan-siluman-bangsapaloh-di-hutan-belantara-kalimantan

Kuntjaraningrat. (2002). Metode Penelitian Masyarakat. Rineka Cipta.

Langaji, A. (2016). Dinamika Aliran Keagamaan Sempalan: Tinjauan Perspektif Sosiologi Agama. HIKMAH, XII(1), 141-162.

Lapidus, I. M. (1991). A History of Islamic Societes. Cambridge University Press.

M. Djunaidi Ghony \& Fauzan Almansur. (2012). Metodologi Penelitian Kualitatif. Ar-Ruzz Media.

Mahjuni. (2017). Orang Bunian di Paloh [Surat].

Malefijt, A. D. W. (1968). Religion And Culture: An Introduction to Anthropology of Religion. Macmillan Publishing Co., INC.

Mardiyati, I. (2011). Perkembangan Pendidikan dan Perilaku Keberagaman Pada Masa Kesultanan Sambas. Walisongo, 19(2), 335-338.

Masyarakat Paloh. (2017). Cerita dari mulut ke mulut tentang orang Bunian di Paloh [Surat]. 
Matthew B. Miles A Michael Huberman. (1994). Qualitative Data Analysis: An expanded sourcebook. SAGE Publication.

Mujiburrahman. (2008). Mengindonesiakan Islam: Representasi dan Ideologi. Pustaka Pelajar.

Mujiburrahman. (2013). Bercermin Ke Barat: Pendidikan Islam Antara Ajaran dan Kenyataan (Cetakan Pertama). Jendela.

Mujiburrahman. (2015). Agama, Media Dan Imajinasi: Pandangan Sufisme Dan IImu Sosial Kontemporer (Cetakan 2). Antasari Press.

Mujiburrahman. (2017a). Agama Generasi Elektronik (Cetakan Pertama). Pustaka Pelajar.

Mujiburrahman. (2017b). Humor, Perempuan dan Sufi. Kompas, Gramedia.

Mujiburrahman. (2018). Orientasi Penilaian BKD Online, Kopertais Wilayah XI Kalimantan Tahun 2018.

Murtadlo, M. (2014). Masjid Kraton Sambas dalam Konstelasi Pembaharuan Islam di Kalimantan Barat. Lektur Keagamaan, 12(1), 207-234.

Mustansyir, R. (2016). Kearifan Lokal Masyarakat Melayu Sambas Dalam Tinjauan Filosofis: Legenda Rakyat, Filosofi Air dan Tradisi (ed) Amin Ma'ruf. Fakultas Filsafat, Universitas Gadjah Mada.

Nottingham, E. K. (1996). Agama dan Masyarakat: Suatu Pengantar Sosiologi Agama, terj. Abdul Muis Nahorang, Ed. CV. Rajawali.

P, C. E. (1944). Religious Dynamics. Journal of the American Academy of Religion, XII(2), 110-112. https://doi.org/10.1093/jaarel/XII.2.110

Pals, D. L. (2012). Seven Theories Of Religion, Terj. Inyiak Ridwan Muzir \& M. Syukri. IRCiSOD.

Paul Reddisha, Penny Toka, and Radek Kundta. (2016). Religious Cognition and Behaviour in Autism: The Role of Mentalizing. Psychology of Religion, 26(2), 96-112.

Polisi. (2017). Pengalaman Polisi di Paloh [Surat].

Rakhmat, J. (2013). Psikologi Agama: Sebuah Pengantar. Mizan Pustaka.

Ridwan, B. (2016). POTRET ORGANISASI KEAGAMAAN DAN RESPON TERHADAP DINAMIKA KEHIDUPAN KEBERAGAMAAN DI SALATIGA. INFERENSI, 5(1), 101. https://doi.org/10.18326/infsl3.v5i1.101-120

Roem, E. R., \& Sarmiati. (2019). Perubahan Sosial Budaya Akibat Media Instagram Bagi Kalangan Mahasiswi di Kota Padang. Jurnal Antropologi: Isu-Isu Sosial Budaya, 21(02), 202-210.

Roland Robertson, ed.,. (1995). Agama: Dalam Analisa Dan Interpretasi Sosiologis., terj, Achmad Fedyani Saifuddin (Cetakan ke-4). PT. RajaGrafindo Persada.

Rota, A., \& Krüger, O. (2019). The Dynamics of Religion, Media, and Community: Online - Heidelberg Journal of Religions on the Internet, 14, 1-20. https://doi.org/10.17885/heiup.rel.2019.0.23945

Rumadi. (2012). ISLAM DAN OTORITAS KEAGAMAAN. Walisongo: Jurnal Penelitian Sosial Keagamaan, 20(1), 25-54. https://doi.org/10.21580/ws.20.1.183

Sanaky, H. (2005). Sakral (sacred) dan profan: Studi pemikiran Emile Durkheim tentang sosiologi agama. laporan). Makalah Diskusi Kelas, Program Doktor [S-3] Universitas Islam Negeri Sunan Kalijaga, Yogyakarta, 6, 1-24.

Sastranagari. (2017, Januari 4). Paloh, Negeri Gaib yang Dipercaya Bersemayam di Pedalaman Hutan Kalimantan. Boombastis.com | Portal Berita Unik | Viral | Aneh Terbaru Indonesia. https://www.boombastis.com/negeri-gaib-paloh/85116

Silalahi, U. (2009). Metode Penelitian Sosial. PT. Refika Aditama.

Suhardi, M., Mulyono, S., Aslan, Syakhrani, H. A. W., \& Putra, P. (2020). Perubahan kurikulum lembaga pendidikan Islam di Sambas pada masa Kesultanan Sambas. Ta'dibuna: Jurnal Pendidikan Islam, 9(1), 034-048. https://doi.org/10.32832/tadibuna.v9i1.2715

Sunandar. (2014). Melacak Hubungan Kesultanan Sambas dan Bugis (Studi Awal terhadap Naskah Tuhfat al-Nafis). Jurnal Khatulistiwa - Journal Of Islamic Studies, 4(2), 117-125.

Sunandar. (2015a). Melayu Dalam Tantangan Globalisasi: Refleksi Sejarah dan Berubahnya Sistem Referensi Budaya. Khatulistiwa, 5(1), 60-73.

Sunandar. (2015b). Politik Identitas Dan Tantangan Globalisasi Masyarakat Perbatasan Dalam Menghadapi MEA 2016. Proceeding of 1st International Conference on ASEAN Economic Community in Borneo Region.

Sunandar. (2015c). Politik Identitas Dan Tantangan Globalisasi Masyarakat Perbatasan Dalam Menghadapi MEA 2016. Proceeding of 1st International Conference on ASEAN Economic Community in Borneo Region.

Sztompka, P. (1993). Sociology Of Social Change. Oxford UK.

Thambun Anyang, Y. (2003). Gambaran Kenyataan Keragaman Hukum Di Kalimantan Barat. Seminar dan Pelatihan Pluralisme Hukum, diselenggarakan oleh HuMA, 1-10.

Thomas F. O'Dea. (1996). Sosiologi Agama: Suatu Pengenalan Awal (Cet-7). PT. Raja Grafindo Persada.

Toffler, A. (1970). Future Shock. Bantam Books.

Toffler, A. (1980). The Third Wave. William Morrow and Company, INC. 
Usman (Camat Paloh). (2013). Daftar Nama Rupa Bumi Wilayah Kecamatan Paloh. Kecamatan Paloh.

Viktor, A. et al. eds. (2014). Sejarah Sosiologi Budaya Bernafkah Komunitas Adat Suku Duano. Paramita, 24(2), 186-199.

Wawancara dengan anggota Pokdarwis. (2017, Juni 7). [Surat].

Wawancara dengan Dukun di Wilayah Paloh. (2017). [Surat].

Yusriadi. (2014). Sejarah dan Perkembangan Orang Melayu di Riam Panjang, Kalimantan Barat. Khatulistiwa, 4(2), 140-149.

Yusriadi. (2019). Identitas Orang Melayu di Hulu Sungai Sambas. Elmans' Institute. 